\title{
OS EFEITOS DA OPRESSÃO HETERONORMATIVA NOS
}

\section{RELACIONAMENTOS HOMOAFETIVOS}

\section{Marcelo Ricardo Rosa}

Mestre em Educação pela USM
Recebido em: 26/04/2019

$1^{\text {a }}$ revisão em: 23/05/2019

Aceito em: 31/05/2019

Berttran, D. E. (2018). Amores invisíveis: Casais longevos da diversidade. São Paulo, SP: Editora Cultura.

\section{RESENHA}

A obra "Amores invisíveis: Casais longevos da diversidade" trata-se de um conjunto de entrevistas com quatro casais, integrantes da comunidade LGBTI, com o intuito de fundamentar as dificuldades e conflitos vividos em meio a uma sociedade em que impera o padrão heteronormativo. A somatória de quarenta capítulos apresenta a introdução, seguido da apresentação das personagens e as conclusões acerca das informações coletadas.

A autoria ficou a cargo de Déa E. Berttran, com formação em Psicologia, além de ter efetuado mestrado e doutorado na área de Psicologia Clínica. Atualmente, é Professora Adjunta I do curso de Psicologia em Santos, no instituto Centro Universitário São Judas, campus Unimonte. Com o ensejo da tese de doutorado, desenvolveu este livro para mostrar as adversidades de gays e lésbicas ao externar o seu relacionamento para o âmbito social.

$\mathrm{Na}$ introdução, a autora destaca o medo da sociedade perante o que foge dos rótulos impostos há muitos, especificamente, cita a autora, no momento em que isto se amparou no modelo do homem europeu. O segredo da relação homoafetiva passou a ser um fator comum, pois não se adequava ao padrão da sociedade, levando-os a invisibilidade e a busca por acolhimento.

A autora, a princípio, inicia os moldes do cenário preconceituoso e conservador do Brasil ao obter dados que confirmam o quadro violento e hostil que incorre quando o assunto é a comunidade LGBTI. É notório o asco a momentos em que o telespectador é introduzido a cenas, implícitas ou explícitas, de personagens televisivos que expressam o amor ou atração por pessoa que compartilham de 
igual sexo. Isso se reflete na agressividade capaz de ocasionar uma morte a cada 19 horas, homicídio propagado pela intolerância a orientação sexual seguida por um indivíduo.

Para aprofundar-se ainda mais neste cenário e trazer a realidade ao leitor, a autora sintetizou entrevistas, que foram realizadas pela web, com quatro casais, sendo dois relacionamentos lésbicos e dois relacionamentos gays. Utiliza-se de nomes fictícios para mantê-los em anonimato, além de alterar algumas circunstâncias para dificultar identificações.

A primeira parte denota o relacionamento de Dani e Nancy, juntas há 40 anos por laço afetivo, sem "ainda", como Dani cita, ter ocorrido o reconhecimento da união em cartório. Neste diapasão, Berttran revela a preocupação relativa de tal ato ainda não ter sido efetivado. Para demonstrar isso recorre ao âmbito jurídico para exemplificar os projetos e leis voltados a questão, cita a decisão de efeito vinculante que autoriza a união estável entre casais de igual sexo, tendo em vista a vedação de qualquer tipo de discriminação, como bem cita a lei maior regente deste pais, vide a Constituição Federal de 1988, além da obrigação de todo o cartório celebrar o casamento homoafetivo. Para haver melhor entendimento disto, insta-se o aprofundamento na estrutura do relacionamento.

Dani adveio de uma família tradicional e só obteve a chance da descoberta sexual ao alçar voo rumo a faculdade, momento em que conheceu uma garota de personalidade oposta à sua. O relacionamento foi desfeito ante as recorrentes divergências e a pressão exercida por sua mãe. Inicia-se o temor na assunção da sua identidade sexual.

Por outro viés, Nancy obtinha uma família diferenciada. Sua mãe sofreu de doença psíquica, o pai era provedor do lar e tinha sete irmãos. Amargava-se em relacionamentos heterossexuais, em que recorrentes eram as fantasias, em que o parceiro assumia a faceta feminina. Ao se envolver com uma amiga, notou que gostava daquele sentimento, embora não a levasse a completude, em vista da grande amizade que aquele relacionamento angariava.

Ao se conhecerem, a dupla de personagens se apaixonou irremediavelmente. Enquanto Nancy desejava viver aquele amor, Dani apartou-se em uma viagem. O único modo de contato entre elas, foram as cartas, que levou Dani a conclusão de que a distância jamais poderia apagar aquele sentimento guardado. Isso incorreu em um enfrentamento, relativo ao que a autora se refere como o legado familiar, que é reproduzido de geração a geração.

Frisa-se que, apesar de ter rompido com a subjetividade ao relacionar-se com o mesmo sexo, não incorreu tal fenômeno quanto a objetividade, em vista de que Dani aplicou o modelo familiar ao seu relacionamento, apreendido com a visão de seus pais. 
Na parte financeira Dani assumiu a herança de seu pai, obtendo lucros nos negócios, enquanto Nancy mantinha-se com igual êxito em seu ramo profissional, embora tenha sido em menor escala pecuniária.

Em relação a família de Dani, a mãe demorou a aceitar e, aos poucos, caminhou para a pacificidade. O irmão de Dani a ouviu confessar a respeito de sua orientação, respeitando, porém, sem querer voltar ao assunto.

Elas viveram esse romance sob a égide da discrição, em que não haviam símbolos para demarcar pertença, como uma aliança, o que gerava o desconforto da inexistência do relacionamento para o coletivo em Dani, principalmente quando Nancy socializava com determinados amigos. O sentimento avassalador do ciúme levou-as a agressões físicas, que, de acordo com elas, já vieram a cessar, ao ponto de mal lembrarem-se qual foi a última briga que tiveram. Com isto, o círculo de amizades fechou-se ao ponto de não haver amigos individuais e se sentirem à vontade em encontros com outros casais gay, apesar de não compartilharem a integralidade de sua vida, nem mesmo neste âmbito amigável.

Dani e Nancy disfarçavam, até certo período, a cama que dividiam, embora já fosse assumidas perante a família. Berttran (2018, p.41), explica que este amor sussurrado é um modo de "resguardar uma esfera que é privada, não a revelando publicamente", para incorrer a uma boa sobrevivência no coletivo. Desta feita, o sentimento de exclusão, dado o enfrentamento social, que o diferente angaria para si, faz com que proteções sejam moldadas para afastar-se das adversidades.

A segunda parte retrata um casal gay, Donato e Tomás, unidos há mais de 30 anos, sem ainda ter realizado questões de união estável ou matrimônio. Conheceram-se em meio as noites paulistanas da década de 80 , ao ponto de demorarem meses até terem o seu primeiro encontro em período diurno.

Advindo de família tradicional e conservadora, Donato tem um irmão gêmeo que, posteriormente, assumiu os negócios da família. Sempre fora inquirido a respeito dos seus gostos e um dia confessou a seu pai, com naturalidade, que era homossexual. Por outra vertente, Tomás, ainda jovem, viu o pai falecer, o que the proporcionou maior grau de liberdade para explorar a sua sexualidade. Tomás cita que não comenta de forma aberta a relação dele com Donato, embora a sua família já tenha plena ciência do que ocorre entre ambos.

Tomás galgava por sua independência, enquanto que Donato encontrava-se na dependência familiar. O pai de Donato, certa vez, financiou uma viagem para a Alemanha, momento em que ele se encontrava firme em um namoro de três anos com Tomás, ele optou por ir, acontecimento que causou o romper, embora trocassem frequentes cartas.

Atualmente, Tomás e Donato vivem juntos, em uma relação igualitária, da qual ambos contribuem para o lar, seja financeiramente ou ao praticar serviços domésticos. 
A autora em um corte metodológico, adentra no mérito da questão de gênero, explanada por Robert J. Stoller, que diferenciou os conceitos de sexo e gênero, sendo, respectivamente, como a diferenciação fisiológica e os estigmas propagados pela sociedade. Portanto, o gênero constrói-se com os dizeres sociais, em que qualidades e defeitos são atribuídos a figura feminina ou masculina.

Desta feita, conclui-se que adotam do legado familiar fatores importantes, um exemplo é o companheirismo vislumbrado em seus pais, porém foram flexíveis ao dividirem as tarefas, não almejarem prole ou o fato de ainda não terem oficializado uma União Estável ou casamento.

Na terceira parte há uma mudança brusca do cenário, ante a um elemento a mais, no caso um filho. Raquel veio de um berço tradicional, em que sua mãe, embora expressasse desejo de ir para a faculdade, dividia sua vida entre o doméstico e os estudos efetuados em casa. Seu pai produzia desfiles em que ela sempre ia, tanto para se divertir quanto para ser os olhos de sua mãe, devido aos ciúmes desta com o marido.

Raquel, que anteriormente contraiu matrimônio heterossexual, é mãe de Osmar, fruto advindo deste relacionamento. Posteriormente, envolveu-se com Sandra, sua assistente no trabalho. Ela cita ter sido impelida a hetenormatividade, embora tenha tido fantasias com mulheres em sua adolescência. Ademais, seu ex-marido a desvalorizava no âmbito profissional e não lhe dava liberdade, o que incitou maiores motivos. Bastou a proximidade e um único toque para que se voltasse a uma união homoafetiva com Sandra.

Por ter sido introduzido jovem a este meio, Osmar conseguiu aceitar bem a mudança, além de que, Raquel dispunha de todas as informações possíveis para que este caminhasse para a aceitação de sua orientação sexual.

Berttran explicita que o divórcio, ao envolver filhos, torna-se conturbado, e nos casos de mudanças positivas como estas, soma-se a aceitação de um relacionamento homoafetivo pela prole.

Em meio a conturbação dos dois últimos anos de um relacionamento difícil, Raquel e Sandra resolveram viajar em um fim de semana, no qual conheceram Ísis, que se tornou companheira de Raquel até os dias atuais.

O romper com Sandra ocasionou uma situação desagradável, em que esta tentou o suicídio, além de ter pego Osmar durante um final de semana e dizer que não o devolveria. O último acontecimento retratado provocou uma mudança drástica na forma de Raquel dirigir sua união com Ísis, aplicando a regra de que não morariam juntas.

Osmar desenvolveu-se em meio ao lar homoafetivo e aprendeu a tolerância. Ficara certa vez desgostoso ao ouvir seu pai xingar os amigos de sua mãe com 
palavras ofensivas, direcionadas a orientação sexual. Com o crescimento, optou por sair de casa e ir para a faculdade, passo importante em sua vida e na vida de Ísis e Raquel, em vista de que o trato feito anteriormente de não morar na mesma residência perdera o sentido.

Desta feita, foram compartilhar igual residência, porém a situação fática agravouse com o retorno de Osmar para casa, após ter se graduado. O que provocou a busca por ajuda terapêutica, que foi um grande auxílio para lidar com a situação.

A autora narra que se denota entre o casal um vínculo de controle. O vínculo é definido como algo multifacetado, dado pelo encontro de pessoas, que produz "um elo estável que, por sua vez, gera o que é chamado de intersubjetividade, ou seja, o tecido grupal do psiquismo; em outras palavras, um espaço psíquico próprio, que só acontece quando existe o plural" (BERTTRAN, 2018, p. 75). Isto ocorre em vista do temor da solidão de Ísis somado a submissão de Raquel no âmbito familiar.

A quarta e última parte retorna a uma união gay, vivida em 1956, um período difícil de incorrer a assunção, perante a sociedade, de ser gay. Somado isto ao fato de que Nestor e Otávio viviam em cidade do interior, em que o preconceito era arraigado, qualquer tipo de contato entre ambos já seria dificultoso. Contudo há mais um óbice a se impor em meio ao casal: o casamento de Nestor.

Eles se conheceram em uma noite na Rodoviária da cidade, conhecida por ser um ponto de encontro gay. Otávio repeliu Nestor ao notar a sua aliança, contudo o destino se encarregou de efetuar a proximidade, quando ambos subiram em igual ônibus e, deste modo, descobriram morar no mesmo município.

Otávio adivinha de família marcada pela rejeição. O pai, fazendeiro, e a mãe, vinda de lar refinado, conheceram-se durante o tratamento de tuberculose, doença que os levou ao isolamento. Casaram-se, porém sua mãe veio a falecer quando ele tinha 11 anos, deixando a cargo a criação de Otávio somente ao pai. Enquanto Nestor possuía 11 irmãos, além da sua família, constituída por esposa e três filhos, dois biológicos e uma adotiva, dado o desejo de sua esposa obter uma menina.

Com a constante inquisição do pai para que Otávio retornasse o namoro com uma garota e a não aceitação da homossexualidade do filho, Otávio se viu compelido a alugar uma residência, próxima a de Nestor. Isto culminou na proximidade dele com a família de Nestor, tornando-se melhor amigo de sua esposa. Incorreu, inclusive, proposta de Nestor para que Otávio retomasse a união com a ex-namorada, para que ambos fossem amantes, sem levantar suspeitas. Algo que não foi aceito por Otávio.

Os lações estreitos provocaram um fim de matrimônio conturbado entre Nestor e sua esposa, sendo aplicado o litígio no divórcio. O casal mudou-se para uma cidade vizinha até obterem a chance de irem para São Paulo. Recorrentes eram as 
vezes em que Otávio e Nestor viajavam para visitar, respectivamente, o pai e seus filhos. O relacionamento passou a ser aceito pelo pai de Otávio, ao ponto de ter se mudado para o litoral paulistano para maior aproximação. Nos últimos anos de sua vida, ocorreu de ir morar com o casal e, embora visse Nestor como um filho, ainda cingia isto com o preconceito.

Ademais, os filhos de Nestor aparentavam gostar de ferir o pai em todas oportunidades, tinham o costume de desaparecer com os presentes e as pequenas coisas que recebiam por parte do casal quando iam passar um tempo com eles. Foi no batizado de seu neto que decorreu a revelação, diante dos irmãos, filhos e genro, porém ele foi coagido a falar sobre o relacionamento dele com Otávio.

O casal acabou por firmar União Estável pela necessidade de atendimento médico por parte de Nestor. Posteriormente contraíram matrimônio ante ao temor do genro de Nestor, advogado, que embriagado determinou ameaças referentes ao patrimônio do casal.

A conclusão da autora a cerca disto é que cada casal, em sua singularidade, conseguiu desenvolver os quatro princípios citados por Alberto Eiguer, ou seja, respeito, reconhecimento mútuo, responsabilidade sobre o outro e reciprocidade dos investimentos.

Os casais apresentados viveram em meio ao preconceito, rejeição, os conflitos internos dado ao poder heteronormativo, além da invisibilidade deste relacionamento ou a mera indiferença de familiares, que sabem, porém, preferem ocultar o assunto. Contudo, por virem de famílias moldadas pela heterossexualidade, flexibilizaram isto no sentido subjetivo, ao mudar os pares, mas não no objetivo, como a cumplicidade presenciada em seus lares, permanecera a mesma. $E$, neste viés, em que a união homoafetiva vivenciada tem de ultrapassar tamanhos óbices, o que se aguarda da sociedade é um modo de empatia, para que estes casais não tenham de viver sobre a sombra de um disfarce ou, simplesmente, no âmbito da invisibilidade.

\section{CONFLITOS DE INTERESSES}

Não há conflitos de interesses.

\section{SOBRE O AUTOR}

Marcelo Ricardo Rosa é enfermeiro pela Universidade do Sagrado Coração, mestre em Educação pela Universidade São Marcos. Trabalha como professor colaborador, ad hoc, no Instituto Nacional de Estudos e Pesquisas Educacionais Anísio Teixeira - INEP. Desenvolve estudos nas áreas da interdisciplinaridade e saúde; avaliação do ensino superior e populações vulneráveis. E-mail: mrosa.ead@gmail.com 